\title{
LA (DES)CONEXIÓN
}

MUJERES Y

NATURALEZA:

PROPUESTAS ECO Y/O

CIBER-FEMINISTAS

\section{Dra. María José Guerra Palmero}

Directora del Instituto de Estudios de las Mujeres de la Universidad de La Laguna y Profesora Titular de Filosofía Moral

Facultad de Filosofía de la Universidad de La Laguna. Campus de Guajara. C/ Molinos de Agua s/n., 38207, La Laguna (España) - Email: mjguerra@ull.es

\section{Resumen}

El objetivo de este texto es reivindicar el papel de la creatividad teórica y política eco y ciber-feminista para ofrecer nuevos imaginarios sociales liberadores como el del cyborg, un nuevo icono. Esto último responde a la subversión epistemológica y metodológica de los ecofeminismos y los ciberfeminismos, opciones teórico-políticas que dislocan y desafían los estériles tópicos de los discursos misóginos. Tales estrategias subversivas son hoy lugar común de los estudios culturales feministas. La reflexión sobre la hibridación y la monstruosidad se incardina en las obras de diferentes autoras de referencia como Donna Haraway o Sadie Plant. La conclusión a la que llegamos es que la utopía de un mundo postgenérico, propuesto desde un ímpetu liberador ligado a las bio/ciber/tecnologías, no puede renegar de la eco-
Palabras clave

Mujeres, naturaleza, cyborg, monstruo, ecofeminismos, ciberfeminismos

Key Words

Women, nature, cyborg, monster, ecofeminisms, cyberfeminisms

Abstract

The aim of this text is to vindicate the role of theoretical and political creativity to propose new social imaginaries for liberation, for example, the cyborg, a new icon. These subversive strategies are today common in cultural studies. In this paper, we reflect on the mutations that technology operates on women in the theoretical and practical intersection between ecofeminism and cyberfeminism. The reflection on the hybridization and monstrosity is connected with the works of different authors as Donna Haraway and Sadie

Plant. We reach to a clear conclusion: the utopia of a post-gendered world has to be proposed linked to a use of bio/cyber/technologies that do not renege on the ecology and culture of life. We assess, in sum, the posthumanist turn from equalitarism and sustainability as normative criteria. 
logía y de la cultura de la vida. Evaluamos, por lo tanto, el giro posthumanista desde criterios normativos igualitaristas y sostenibles.

\section{Introducción}

Mary Shelley, hija de Mary Wollstonecraft, fue, como su madre, una mujer enfrentada a las convenciones sociales. Ambas exigieron un lugar público en el mundo desde el que hablar y escribir, demandaron poder trabajar como escritoras para ganarse la vida y desafiaron el conformismo pacato del matrimonio burgués. Todas las mujeres que nos atrevemos a escribir y a hablar, a reclamar la palabra pública, somos sus herederas. El feminismo ha exigido libertad para las mujeres, ha desbrozado las implicaciones de la idea de igualdad y ha mante- nido contra viento y marea la bandera de la solidaridad. Más allá de las semejanzas y de las diferencias, la liberación de las mujeres se propone con dimensión universal. De las derivas teóricas feministas actuales, exploramos, en este texto, algunas de las propuestas eco y ciberfeministas que lidian con el tópico posthumano de la monstruosidad y con la dislocación de la ontología de manera que imaginan la posibilidad de un mundo postgenérico.

\section{Objetivos}

El objetivo de este texto es reivindicar el papel de la creatividad teórica y política ecofeminista y ciber-feminista para ofrecer nuevos imaginarios sociales liberadores.
Nuevos iconos, como el cyborg, enfrentan los estigmas seculares asociados a la "monstruosidad" de las mujeres ligado a la desvalorización y subordinación de las mujeres.

\section{Metodología}

La metodología que hemos utilizado es la reconstrucción teórica-crítica de tesis y argumentaciones usando como artificio literario "inapropiado" el motivo femenino del patchwork. Esto supone reivindicar modos alternativos de pensar y presentar los referentes teóricos, desafiando el pseudo-objetivismo que enmascara a las subjeti- vidades dominantes. El que el sujeto esté siempre situado y localizado es un principio del feminismo del punto de vista. Esto último responde a la subversión epistemológica y metodológica de los ecofeminismos y los ciberfeminismos, opciones teórico-políticas que dislocan y desafían los estériles tópicos de los discursos misóginos. 
Tales estrategias subversivas son hoy lugar común de los estudios culturales feministas. La reflexión sobre la hibridación y la monstruosidad se incardina en las obras de diferentes autoras de referencia como Donna Haraway o Sadie Plant.

"Hubo dioses que escucharon la súplica: pues los cuerpos mezclados de los dos se unieron y llegaron a tener la apariencia de uno; igual que si se injertan ramas en una corteza, se las ve unirse al crecer y madurar juntas, así, cuando sus miembros se unieron en apretado abrazo, no son dos sino una forma doble, $y$ no se podría decir si era hombre o mujer: las dos cosas y ninguna parece." Ovidio

\section{La mujer como monstruo}

Consultemos un diccionario y enumeremos las distintas acepciones de la palabra monstruo. El monstruo es aquel ser cuya forma difiere de los demás de su especie o aquel que responde a una mezcla de especies (sirenas, minotauros, unicornios, esfinges,...). La maldad y la fealdad se tilda de monstruosa. El de monstruo es por tanto, un término cargado semánticamente de valor moral y estético negativo. Deformidad y enormidad son también rasgos que lo acompañan. Es a la vez defectuoso y excesivo. No responde al canon de lo "natural”, es un prodigio que suscita horror y espanto.

El monstruo es un ser híbrido, mezcla de componentes no proporcionados ni afines. La imagen cinematográfica del monstruo de Frankenstein que todos llevamos impresa en nuestra mente es la de un ser suturado y lleno de costurones. No está hecho de una sola pieza. El monstruo es siempre una criatura fronteriza que se instala o bien entre dos especies animales - lo que ahora referimos con la palabra "trans- génico", por ejemplo, el patentado y biotecnológico oncoratón- o bien entre el animal y el hombre - los "humano-animales" de La Isla del Doctor Moreau, por no hablar de la posibilidad del xenotransplante- o bien entre el hombre y la máquina - el cyborg o simbionte (ROSNAY, 1996) -. El monstruo de Frankenstein desafía, además, la nítida línea que separa la vida de la muerte, pero lo esencial es que el zurcido de las partes humanas muertas produce un ser, vigorizado eléctricamente por el rayo, que no es reconocido como humano.

Más allá de todas estas hibridaciones, la revolución informática nos ha traído otra posibilidad: la máquina humanizada, por ejemplo, Hal, el autosuficiente ordenador de 2001, una odisea del espacio, del recientemente desaparecido Kubrick, es también monstruoso y rebelde y osa desafiar las órdenes de sus amos. Philip Kerr en El infierno digital, nos inquieta al relatar como un edificio inteligente, por error - debido a su gran capacidad de autonomía-, copia 
unos juegos de ordenador de un hijo de los ingenieros y empieza a eliminar a todos los habitantes humanos que atrapa en su interior volviendo a desplegar el drama de la máquina contra el hombre. Otros ejemplos, como los Blade Runner de Ridley Scott se reconocen como humanos, demasiado humanos, para ser sometidos a eliminación y reciclaje. Pero aún hay más, la conexión en redes de las máquinas de la información crean un supraorganismo planetario cuyo tejido cerebral combina neuronas biológicas y neuronas de silicio, del que los que jugamos a cibernautas formamos parte.

La ciencia y la imaginación que primero se dieron la mano en la literatura de cienciaficción ahora tienen su campo de pruebas en el laboratorio biotecnológico o en la simulación de la realidad virtual. Las fabuladas quimeras son ahora posibles. Sus componentes serán moleculares o digitales. Pero, la producción en serie de monstruos es una posibilidad real. A nadie escapa la naturaleza monstruosa de Dolly. Parece, pues, un deber moral volver a pensar sobre los monstruos.

La respuesta habitual frente a los monstruos ha sido el terror y el ansia exterminadora. Los monstruos violan el "orden natural” y, por lo tanto, generan caos y desorden. Inhabilitan las reglas y demandan excepciones. Destruyen las certezas sociales tan difícilmente constituidas. Son un fallo a subsanar. Hay que perseguirlos incesantemente e intentar acabar con esa lacra de la humanidad - tal como el doctor Fran- kenstein persigue, enmarcado en el frío paisaje polar, a su alter ego defectuoso -. El creador del monstruo debe cercenar su existencia y así restituir la justicia de las cosas, la justa medida - el viejo ideal griego de la proporción armónica- que el exceso defectuoso del monstruo desafía.

La otra respuesta, la que sugiere Mary Shelley, madre literaria de Frankestein y de su monstruo, es la compasión. El monstruo es un ser abandonado y solitario, privado del calor de los otros seres humanos que retroceden aterrorizados ante él. Su creador no le concede una Eva que lo acompañe y ante tanto frío despecho su vulnerabilidad se troca en violencia asesina y brutal. No hay Bella que conjure con su sacrificio la agresividad de la Bestia. Sin embargo, ¿por qué atrevernos a hablar de la mujer como monstruo?.

Sirenas, parcas, arpías, brujas, hadas, en clave mítica o suegras, cotillas, mujeres fatales, solteronas, feministas, histéricas, lesbianas, en clave cotidiana, el caso es que lo monstruoso se declina en femenino. Horror y prodigio conjugados nos obligan a volver a las sugerencias acotadas por el diccionario. Las mujeres diferimos del hombre, encarnación de la esencia de la especie, modelo de la auténtica, apropiada y adecuada humanidad. La alteridad se niega al despreciarla. Hemos sido pensadas, por el contrario, como humanidad disminuida, y esto, precisamente, por nuestra supuesta cercanía a la naturaleza. La forma fue asignada por Aristóteles al varón, la 
amorfa materia a las mujeres. Eva es una copia imperfecta del varón, sólo una superflua costilla sirve para crear a tan dudoso ser. La carencia de alké es lo que caracteriza en los textos homéricos a las mujeres, siendo éste algo así como el "ardor guerrero" (Madrid, 1999). Seres asustadizos e inconstantes, las mujeres son definidas como seres defectivos, carentes, subhumanas, en suma, aunque necesarias para la tarea de la reproducción. Este último "hecho" es lo que, además, refuerza su conexión con la naturaleza: los ciclos femeninos parecen estar emparentados con los ciclos lunares y con los estacionales regulando la fertilidad - el rapto violento de Hades interrumpe el incestuoso idilio entre Ceres y Perséfone-. Nuestro lugar natural nos conmina a la renovación y conservación de la vida. El objetivo número uno de toda sociedad patriarcal es asegurarse del uso conveniente de esta capacidad para ello las virtudes propias de las mujeres serán -virginidad, castidad y fidelidad-. Hay que asegurar la propiedad privada de los hijos por parte del Pater familias y desconfiar de las mujeres en las que siempre habita la semilla de la traición. El monstruo puede aparecerse como prodigio de belleza y desatar, al modo de Helena de Troya, la más cruenta de las guerras.

Carentes, defectuosas, desproporcionadas incluso frente a la belleza perfecta de la mujer ideal ${ }^{\mathrm{i}}, \mathrm{y}$, sin embargo, naturales, a las mujeres se les ha negado, se les ha recortado la titularidad humana. La palabra y la acción pasan a ser las marcas de la ciudadanía, pero les serán sustraídas una y otra vez a las mujeres. Silencio, pasividad y obediencia al amo será lo "apropiado" para una mujer cuyo morar corresponde estrictamente al oikos, alejada de la discusión humanizadora del ágora.

¿Qué ocurre si la mujer osa trascender las prohibiciones patriarcales? Al defecto constitutivo e irremediable tendremos que sumar la asignación de la monstruosidad ética y estética. Todas las transgresoras nos aparecen como paradigmas del mal: Eva, por desobediente, Pandora, por curiosa, Hera, por celosa, Clitemnestra, por infiel, Aspasia, por locuaz, Cleopatra, por ávida de poder... Todas encarnan el mal que trae el desorden y la destrucción. Son pues monstruos y contraejemplos para las buenas mujeres que deben estarse quietecitas y calladitas.

La madre de Frankenstein, Mary Shelley, y su madre, Mary Wollstonecraft fueron monstruos para su época. Mujeres enfrentadas a las convenciones sociales, exigiendo un lugar público en el mundo desde el que hablar y escribir, demandando poder trabajar como escritoras para ganarse la vida y desafiando el conformismo pacato del matrimonio burgués. Todas las mujeres que nos atrevemos a escribir y a hablar, a reclamar la palabra pública, somos sus herederas. La madre de Frankenstein es nuestra madre. ¿No nos obligará esto a compadecernos, a aliarnos, a confraternizar con los monstruos? 
El feminismo ha exigido libertad para las mujeres - de la civil a la sexual o a la reproductiva- ha desbrozado las implicaciones de la idea de igualdad - de la económica a la polémica propuesta de la democracia paritaria pasando por la estrategia de la acción afirmativa-, y ha mantenido contra viento y marea la bandera de la solidaridad. Más allá de las semejanzas y de las diferencias, la liberación de las mujeres se propone con dimensión universal. La irrupción del multiculturalismo ha propiciado que los feminismos hagan profesión de pluralismo y pongan las bases del diálogo intercultural. Las feministas del Norte no olvidan a sus "hermanas" del sur, ni a los hijos e hijas de estas, sometidas no sólo a la opresión patriarcal - las cifras de la violencia contra las mujeres son escalofriantes- sino al injusto reparto del pastel de la economía global que redunda en feminizar la pobreza. Podemos hablar de una comunidad discursiva feminista planetaria (Jaggar, 1998:7-31) de la que el foro alternativo de Bejing en 1995 dio fe.

Pero hoy, también, las redes de la solidaridad las extiende la teorización feminista más allá de las fronteras de lo que podemos denominar "humano". En concreto, algunas variantes ecofeministas las extienden hacia nuestro pasado evolutivo haciéndose cargo de los lazos que nos unen a los animales y a la naturaleza. La mujer ha sido siempre naturalizada y animalizada: asimilada a la serpiente seductora y venenosa o a la coneja reproductora, tildada de zorra o de vaca y comparado su discurso con el parloteo del loro. Este aproximar a la bestialidad a las mujeres ha sido una vieja estrategia patriarcal para reafirmar la jerarquía del amo. La consideración o relevancia moral de los animales se pone sobre el tapete sobre todo en las culturas anglosajonas. Nuestro retraso en este tema es considerable: justo ahora contamos con la traducción del Animal Liberation de Peter Singer, escrito en el año 1975. Pero todavía más extravagante nos pueda parecer la nueva corriente de solidaridad que se proyecta hacia lo maquínico. Nuestro hábitat, nuestra morada aparece plagada de artefactos con los que mantenemos relaciones simbióticas, los ordenadores nos conectan a una red neuronal de alcance global, la automatización irrumpe en todos los ámbitos de la vida. Nuestra ecología doméstica y cotidiana troca de natural a artificial. Nos fusionamos con distintos dispositivos en una máquina total, pluralizada y compleja que cuestiona nuestros fijos y unitarios modos de identidad. Las nuevas entidades que se generan -cyborgs- no tienen historia familiar que contar, están más allá del complejo de Edipo y su inconsciente se mueve a golpe de impulsos eléctricos, maquínicos, que navegan por el interior de cables de fibra óptica.

Las reflexiones del eco y del ciberfeminismo, a las que vamos a aludir en breve, nos producen vértigo moral, suponen adentrarse en un territorio desconocido y presenciar como la racionalidad y la imagi- 
nación se enlazan proteicamente generando infinidad de formas fugaces que provocan turbulencias infatigables. El mundo va quedando despojado de las viejas certezas y se teje un laberíntico hilo que va desde el caldo originario habitado por bacterias autorreplicantes a máquinas, asimismo, autorreplicantes que van cobrando autonomía a pesar de sus confiados creadores. El papel de los seres humanos en esta narrativa es dudoso. La apuesta ecofememista y ciberfeminista es la de rehabilitar la metáfora del tejer como nueva visión que nos permita solidarizarnos y compadecernos de nuestros ancestros y acompañantes actuales, las bestias, y de los quiméricos, ya sean de creación biotecnológica o hijos/as del silicio. El vértigo categorial acompaña al vértigo moral: a las mujeres, afirman algunas voces, forzadas a identificarnos con la naturaleza y con el autómata al que se le descuenta la conciencia, nos toca la tarea de conculcar la distinción entre lo animal, lo humano y lo artificial. La tarea es objetar el mapa de las categorías y volver a cartografiarlo de nuevo desde nuevas coordenadas que desactiven los vectores de opresión.

\section{Ecofeminismos: de la naturalización de las mujeres y de la feminización de la naturaleza}

Las modulaciones de la conexión mujernaturaleza dan lugar a las distintas variedades de ecofeminismosii ${ }^{i i}$ K. Warren nos ofrece una tipología de estas conexiones al abordar la complejidad de las interrelaciones entre los diferentes feminismos ${ }^{\mathrm{iii}} \mathrm{y}$ los diferentes planteamientos ecologistas ${ }^{\text {iv }}$ :

1. La conexión histórica la sitúa esta autora en la denuncia de la génesis del racionalismo occidental ligado al patriarcado capitalista en la que se justificó la posesión y la utilización de la naturaleza y de las mujeres debido a su inferioridad $^{v}$. El complejo histórico de la Modernidad quedó sostenido por la sumisión de la naturaleza y las mujeres. To- do aquello que se destinaba a ser dominado, entre ellos los pueblos de las tierras colonizados o las clases populares, se naturalizaba -se entendía como primitivo y tosco- o se feminizaba. Naturalización y feminización, las dos caras de la misma moneda, servían de estrategia ideológica para subordinar y justificar la sumisión. María Mies (1997a: p.70) piensa que el holocausto de las brujas en la primera modernidad fue el cimiento para edificar el nuevo modelo de patriarcado capitalista y su invención de una nueva "feminidad" sometida, débil y "romantizada" (Mies, 1997b: 197-238) cuya elaboración más precisa 
debemos a Rousseau. Primero hubo que acabar con los contraejemplos a la subordinación. Las mujeres no podían vivir solas, poseer conocimientos exclusivos como curanderas o herboristas, ni ser independientes ni autosuficientes. Demonización y hoguera fue el eficaz tratamiento.

2. La conexión conceptual denuncia el marco dualista ${ }^{\mathrm{vi}}$ y axiológicamente asimétrico en el que se han situado a la mujer y a la naturaleza del lado de la irracionalidad, la emoción y el cuerpo frente a la racionalidad, la mente y la cultura. La dicotomía no es igualitaria sino que uno de sus términos ostenta el valor y el correlativo el disvalor. Esto se traduce en términos jerárquicos como justificación de la superioridad frente a la subordinación. Los marcos conceptuales de referencia sancionan la dominación de las mujeres y la naturaleza. Algunas estrategias eco y ciberfeministas plantean relativizar y alterar las categorías de lo animal, lo humano y lo artificial con el fin de cercenar el motivo del dominio, con el fin de "curar las heridas".

3. La conexión empírica nos habla de la situación presente de las mujeres en el mundo, en los países del Tercer mundo las mujeres se enfrentan a la contradicción entre deterioro medioambiental contaminación y expolio- y subsistencia. Su trabajo como proveedoras de alimentos y necesidades básicas de la familia hace visible que para subsistir hace falta cuidar y regenerar los recursos naturales. Aquí vemos como el Ecologismo de los Pobres se entrecruza con la atención ecofeminista ${ }^{\mathrm{vii}}$. En los países desarrollados y dado que los peligros sobre la salud que genera la industrialización afectan más a las poblaciones más desfavorecidas, las mujeres, debido a su rol de cuidadoras, han protagonizado numerosas luchas contra la instalación de focos contaminantes. Estos "hechos" parecen documentar que dada la preocupación básica de las mujeres por atender a las necesidades de los otros su sensibilización ante el daño medioambiental es más inmediata y radical. Las políticas del desarrollo son acusadas aquí de irresponsabilidad frente a la salvaguarda de la satisfacción de las necesidades básicas relacionadas con la alimentación y la salud (Shiva, 1997).

4. La conexión epistemológica (Gómez: 1998, 211-251) y metodológica pretende reivindicar el conocimiento silenciado en la gestión de la supervivencia y en los trabajos agrícolas y ganaderos de las mujeres. La desvalorización de lo que hacen o saben las mujeres como campesinas y en su trabajo doméstico ha sido la coartada para introducir métodos "científicos" e "intensivos" que en la mayoría de los casos resultan tan agresivos con la tierra que o la deterioran o la envenenan, haciendo además depender a los pequeños agricultores de 
la producción industrial de fertilizantes y de las multinacionales de las semillas modificadas. La denuncia del reduccionismo cientificista que aísla unos elementos de otros sin dar cuenta de las interconexiones es el objetivo aquí, frente a una comprensión holista de lo orgánico en la naturaleza que representaría, en el terreno de la ciencia, la peculiar visión de la biología de la genetista B. McClintock (Fox Keller, 1991).

5. La asociación simbólica entre naturaleza y mujer es tan extensa y polívoca en nuestra cultura que difícilmente podemos escapar a ella. Aislando algo de tal complejidad, muchas autoras ponen el énfasis en las similitudes en el lenguaje para aludir a la conquista, dominio, violación o penetración de la naturaleza y/o de la mujer. La fierecilla domada de Shakespeare nos puede dar la pauta de la necesidad de un proceso de domesticación de la naturaleza indómita que habita a la mujer. En palabras de Warren "Así el lenguaje que feminiza a los animales y a la naturaleza animaliza y naturaliza a las mujeres..." como estrategia ideológica de inferiorización.

Todas estas conexiones hablan del descrédito y sometimiento del par mujer/naturaleza, pero qué decir de las connotaciones positivas de ideas casi sagradas como la de "Madre Tierra" o "Madre Naturaleza". El tramposo juego ideológico de la degradación de lo real -mujeres o naturaleza- y exaltación posterior de lo degradado como ideal mistificado ha sido desbrozado por $\mathrm{C}$. Amorós y A. Valcárcel al caracterizar la misoginia romántica (Amorós, 1992). La coartada de la idealidad sirve a efectos de contrarrestar el efecto dominante de la inferiorización que justifica la subordinación e incluso la violencia. M. Mies opina que la "romantización” de las mujeres, los salvajes y la naturaleza corre en paralelo a su degradación. Esta operación actúa como "nostalgia de plenitud" nunca alcanzable de lo que el hombre "civilizado" ha perdido al cortar el cordón umbilical con la naturaleza.

6. La conexión política enlaza con la conexión empírica al poner de manifiesto el activismo local de base liderado por mujeres que han visto como se conjugaban sus exigencias feministas -por ejemplo, que se les asignara credibilidad pública- con sus reivindicaciones ecologistas relativas a garantizar un entorno sano y apto para la supervivencia. Estos motivos conjugados han operado sobre la base de la idea de solidaridad entre mujeres del Norte y del Sur y han servido de freno a los efectos fragmentadores en la teoría feminista de algunos enfoques de la cuestión multicultural ${ }^{\text {viii }}$. El protagonismo más que a la discusión académica se le ha dado a las actividades de las comunidades locales. Luchas tan dispares como la de las alemanas contra 
el tráfico de residuos nucleares ${ }^{\mathrm{ix}} \mathrm{o}$ las de las mujeres Chipko en la India (Shiva, 1995:99-149) expresan una conexión ecopolítica feminista.

Pero el debate teórico, aún cuando no cuestiona la solidaridad, si nos ofrece distintos modos de entender la conexión entre defensa de los derechos de las mujeres y defensa de la naturaleza. A grandes rasgos, podemos decir que una línea de demarcación se puede situar entre quienes acuden a la premisa esencialista y biologicista - cuya tesis sería que dado que las mujeres somos generadoras y regeneradoras de vida mostramos un lazo más fuerte con la naturaleza y con sus potencialidades de cuidado y armonía- y quienes abundan en la premisa social constructivista - el hecho biológico de la maternidad no es lo sustantivo, sino el rol impuesto por el patriarcado del cuidado y sus interpretaciones culturales-. El caso es que desde esta última premisa puede operar tanto la convicción ecofeminista, asumiendo que el cuidado ha sido desvalorizado y que, por lo tanto, hay que rehabilitando reconociendo social y económicamente el trabajo de la mujer que ha sido invisibilizado al ser tachado de "natural", como la propuesta de desconectar de una vez por todas mujer y naturaleza para optar a las atribuciones sociales valoradas que quedan del lado de la razón, la cultura y lo masculino. La preocupación ecologista, a resultas de esta última opción, no tendría que ser ningún privilegio femenino sino universalizable, esto es, de todos, hombres y mujeres. No habría ningún privilegio de las mujeres para "conectar" antes con la naturaleza y asumir su salvaguarda. No obstante, esta opción, que suele coincidir con feminismos ilustrados, liberales o socialistas - de distinta manera la analiza, por ejemplo, el ecosocialismo de M. Mellor (1997:11-22)-, si que se muestra dispuesta a desmontar las conexiones que antes, siguiendo a Warren hemos llamado histórica, conceptual y simbólica-. La desconexión en todos los niveles de análisis del vínculo mujer-naturaleza desactivaría el ecofeminismo como propuesta con personalidad propia.

¿Qué implicaciones puede tener esto para las diversas posiciones de la ética ecológica? Numerosas, sin duda. Los ecofeminismos esencialistas conjugaran bien con posiciones bio y ecocentristas. Las connotaciones espiritualistas y místicas podrán sumarse a este bloque rescatando, a veces, a nuestro juicio, de forma no demasiado rigurosa con las tradiciones invocadas, elementos de sabidurías orientales ${ }^{\mathrm{x}}$. En este sentido, también es de reseñar la problematicidad de las relaciones mujeres-animales y la consideración del status moral de éstos (Gaard, 1993; Donovan, 1993). No obstante, el contenido social que imprime el feminismo hace que, aún para las versiones esencialistas, no podamos incluirlas como ejemplos puros de ecoéticas ambientalistas. Los límites entre opciones son muy borrosos. De hecho, el trabajo de autoras como Mies y Shiva pueden ser consideradas sin 
asomo de sospecha como socio-eco-éticas dado el peso que dan a la desigualdad mujer y hombre en el patriarcado capitalista y neocolonial haciendo protagonistas a las mujeres pobres del tercer mundo de la lucha ecológica. Dejando de lado los presupuestos esencialistas nos encontramos con posiciones nítidamente ecosociales.

Para finalizar esta mera presentación podemos acordar que los puntos esenciales de convergencia ecofeminista, según el análisis de B. Holland-Cunz son los siguientes:

“...(i) hay importantes puntos en común entre la represión de la naturaleza y la represión de la mujer; (ii) es necesario entender el carácter de esta relación para toda comprensión cabal de la represión de la naturaleza y de la represión de la mujer; (iii) la teoría y la práctica feminista tienen que incluir una perspectiva ecológica; y (iv) las soluciones a los problemas ecológicos deben incluir una perspectiva feminista. ${ }^{\text {}}{ }^{\circledR i}$

Se señalan así una serie de elementos teóricos típicamente ecofeministas: la crítica de las formas de pensamiento dicotómicas naturaleza/sociedad, mujer/hombre, cuerpo/mente, una referencia enfática al ejer- cicio político y la realidad vital y social de la mujer-; la exigencia de relacionar teóricamente todas las formas de represión (sexismo, racismo, dominio de clase, explotación de la naturaleza, explotación del tercer mundo) y un consiguiente internacionalismo solidario, "una ética política de democracia de bases y antiinstitucional, la idea de "sobrevivir" frente a unas circunstancias sociales patriarcales y hostiles para la naturaleza, y una actitud positiva ante la utopía.”(Holland-Cunz, 1996:54)

Entenderemos, pues, por ecofeminismo un espectro de enfoques que, desde la perspectiva de género, se ocupan de la crisis ecológica y correlacionan la dominación y la explotación de la naturaleza y de las mujeres. La variabilidad de énfasis, que van desde la filosofía natural hasta la sociología pasando por la crítica de la ciencia y de la historia, hace de esta temática un territorio abigarrado y diverso. No obstante, la voluntad de muchas de sus variantes de "tender puentes" a los animales y a los ecosistemas nos plantea una nueva forma de vértigo moral al abogar por la relevancia moral de la misma naturaleza.

\section{La reivindicación del monstruo}

La ecología maquínica se nos ha impuesto de manera amable, pero contundente. Muchos de nosotros sin un ordenador no somos nada, nuestra memoria se almacena en sus archivos, nuestro trabajo queda registrado hora a hora. Hemos tenido que conectarnos a la Red para beneficiarnos de sus cruces y estaciones. Mantenemos el contacto con amigos y colegas a través del correo electrónico abundando en una nueva ecología social que nos permite despegarnos del aquí y ahora de un modo 
totalmente simultáneo. Los más entusiastas se enganchan a las cibertertulias, grupos de charla, animados por los fines más variados: desde aficiones comunes hasta el flirteo. Cada vez hay más personas que trabajan desde casa sin tener que desplazarse. Habitamos en Telépolis (Echevarría, 1994 Y 1996). Nuestra ecología mental y social, por utilizar la tripartición de Guattari (Guattari, 1996), se está transformando. Aceleradamente, en los últimos años, la tecnología informática está afectando a nuestra forma de vida.

"El ciberespacio apareció como una zona incorporal más salvaje que el salvaje Oeste, más vigoroso que la carrera del espacio, más sexy que el sexo, y mucho mejor que caminar por la Luna. Era la última frontera de las fronteras, la más pura de las islas vírgenes, el más nuevo de los territorios, una realidad diseñada según las especificaciones humanas, una zona artificial madura para un proceso de colonización infinito, capaz de satisfacer cualquier deseo final, especialmente el de escapar a la "carne” (Plant, 1998:177-8).

Desde el punto de vista de Sadie Plant, la metáfora que ha ganado la partida histórica al ser capaz de lidiar con la complejidad es la de la red y la red remite a la trama y a la urdimbre, al telar, paradigma de la máquina femenina, la que mezcla los hilos, y a cuya imagen y semejanza se articula la base tecnológica de la informática. Prefigura así, poniéndonos bajo la invocación de otra soñadora, Ada Byron Lovelace, inventora de la Máquina Analítica, un futuro simbion- te en el que la distinción entre máquina y humano se inhabilita -según el test de Turing, desde que la primera miente o simula, se impide saber quién es quién- $y$ en el que la diferencia entre los sexos se disuelve bajo el juego de las identidades/máscaras virtuales.

Pero el trabajo de Sadie Plant, que analiza la tecnocultura, viene precedido del de Donna Haraway que remite a la situación de las mujeres, como criaturas fronterizas, como monstruos, en las coordenadas de la tecnociencia. Nacido en el tiempo de la pluralización y aceptando la inserción en un mundo tecnológico, se plantea tanto atender a parcialidades permanentes como no perder de vista la búsqueda de vínculos poderosos. El gran acontecimiento al que asistimos es el nacimiento del cyborg. Pero, ¿qué es un cyborg?

“...una criatura híbrida, compuesta de organismo y máquina... se trata de máquinas y organismos especiales, apropiados para este final de milenio. Los cyborgs son entes híbridos posteriores a la segunda guerra mundial compuestos, en primer término, de humanos o de otras criaturas orgánicas tras el disfraz -no escogido- de la alta tecnología, en tanto que sistemas de información controlados ergonómicamente y capaces de trabajar, desear y reproducirse. El segundo ingrediente esencial en los cyborgs son las maquinas, asimismo aparatos diseñados ergonómicamente como textos y como sistemas autónomos de comunicación.” (Haraway, 1995:62) 
Haraway nos sitúa frente a "la construcción de la naturaleza como un proceso cultural fundamental para gentes que necesitan y que desean vivir en un universo menos invadido por las dominaciones basadas en la raza, en el colonialismo, en la clase, en el género y en la sexualidad" y aboga por el reconocimiento de aquellas

“..criaturas fronterizas -simios, cyborgs y mujeres-, que han ocupado un lugar desestabilizador en las grandes narrativas biológicas, tecnológicas y evolucionistas occidentales. Son literalmente monstruos, ... Los monstruos poseen un significado... Las formas altamente conflictivas e independientes que adquiere el poder de estos monstruos pueden ser signos de mundos posibles, de los cuales se responsabilizan con toda seguridad." (Haraway, 1995:63)

Su teoría invoca a los "otros inadecuados": aquellos que rehusan adoptar tanto la máscara del "yo" como del "otro", ofrecidas por las narrativas dominantes de la identidad y de la política, aquellos que responden a nuevas geometrías relacionales al margen de la dominación, la inclusión o la oposición, al margen del dualismo dicotómico que eleva un término para denigrar al otro, tal y como propone Trinh T. Minh (Haraway, 1995:64-65).

Su tesis actúa de antídoto contra las estrategias naturalizadoras de las opresiones porque "las relaciones humanas históricamente específicas con la "naturaleza" deben ser imaginadas -lingüística, ética, científica, política, tecnológica y epistemológica- mente- como genuinamente sociales y activamente relacionales." La utopía de Haraway pasa por plantearnos qué tipos de personas queremos ser: en su caso, ni amos ni sujetos alienados, sino "agentes humanos múltiplemente heterogéneos, no homogéneos, responsables y conectados." (Haraway, 1995:66)

Desde este enfoque, en el que lo humano se congracia no sólo con las mujeres, sino con los animales y las máquinas - con los que nuestra civilización establece una matriz jerárquica y dominadora-, las metanarrativas replican el relato canónico del viejo Sujeto del monoteísmo y de sus "herejías seculares" reacias a aceptar nuestra fragilidad, mortalidad y finitud. Objetar el orden sexo/genérico presente que es, también, un orden moral normativo, implica apostar por las criaturas fronterizas y bastardas, por los monstruos, por su inadecuación y reivindicar su presencia justo para desactivar las imposiciones identitarias que suelen traer consigo exclusiones, opresiones y jerarquía. Haraway exclama: “¡Cyborgs para la supervivencia de la tierra!” (Haraway, 1995:67) señalando el fin de un paradigma binario y jerárquico que si se obstina en persistir nos arrojará al desastre.

De lo que se trata, por tanto, es de reconstruir las ciencias que asignan un papel a la humanidad conforme a otros modelos narrativos. La naturaleza, ese multívoco concepto es deudor de determinadas narrativas y nuestro objetivo es desmantelarla para optar a reinventar otra naturaleza en la 
que la hegemonía masculina quede disuelta. La ciencia no es objetiva, ni pura, ni neutral, está cargada de valores, de valores sociales que se corresponden con el sistema de dominación vigente. En palabras de la misma Haraway:

“...las historias científicas no son inocentes... Es también verdad que ninguna historia es ajena a las reglas narrativas que prevalecen dentro de un género específico, en este caso, dentro del discurso de la biología. Desmitificar estas reglas es importante para mí. La naturaleza es algo construido, constituido históricamente, no se descubre desnuda en un lecho de fósiles o en una selva tropical. Existe una competición por la naturaleza y las mujeres han entrado a saco en ella. Algunas tienen la autoridad social para escribir historias científicas.

Esto es una novedad." (Haraway, 1995:177)

Para descoyuntar las narrativas dominantes, Haraway inspirándose tanto en el trabajo de socavamiento crítico del postmodernismo como en la eclosión multiculturalista, plantea la ruptura de las fronteras entre lo animal y lo humano.

"Ni el lenguaje, ni el uso de herramientas, ni el comportamiento social, ni los acontecimientos mentales logran establecer la separación entre lo humano y lo animal de manera convincente." (Haraway, 1995:257)

Reniega así de la distinción cultura/naturaleza. O ¿es qué acaso los etólogos no hablan de culturas de diferentes grupos de primates o de grupos familiares de delfines qué incluso tienen variantes dialectales? Aprender la lección de la biología evolucionista implica difuminar el corte entre animales y humanos. Pero la cosa no acaba aquí. El dualismo mecanicista encarnado en el fantasma en la máquina se desvanece porque las máquinas postcibernéticas son autónomas.

Sin embargo, el afán disolvente de Haraway no se contenta con aproximarnos a animales y máquinas. El nuevo mito es el del cyborg y nos remite tanto a fronteras transgredidas como a fusiones poderosas. El caso es desactivar todos los dualismos animal-máquina, mente-cuerpo, idealismomaterialismo, femenino-masculino-. No hay que tener miedo a reconocer el parentesco, la común filiación, con animales y máquinas ${ }^{\mathrm{xii}}$.

Se trata, por tanto, de defender lo monstruoso y lo ilegítimo como mitos de resistencia que nos hablan de afinidades nunca de identidades, de hecho, la debacle del dualismo cortocircuita la distinción genérica entre lo masculino y femenino:

El cyborg es una criatura en un mundo postgenérico. No tiene relaciones con la bisexualidad, ni con la simbiosis preedípica, ni con el trabajo no alienado u otras seducciones propias de la totalidad orgánica, mediante una apropiación final de todos los poderes de las partes en favor de una unidad mayor. En un sentido, no existe una historia del origen del cyborg según la concepción occidental: una ironía final, puesto que el cyborg es también el terrible telos apocalíptico de las 
crecientes dominaciones occidentales de la abstracta construcción de individuos; un último yo no atado finalmente a ninguna dependencia, un hombre en el espacio. (Haraway, 1995:255)

¿Cuál es la finalidad de sembrar este caos categorial? ¿A qué vértigo intelectivo y moral se nos arroja? Haraway piensa que actuar sobre nuestros modos de pensar es necesario para encontrar una nueva estrategia liberadora, una estrategia al servicio de la reconciliación, en la que la dominación y la guerra no sigan siendo alimentadas por la coartada categorial de lo superior y lo inferior, de lo masculino y lo femenino, de lo humano y lo animal, de lo humano y lo maquínico. Su opción es una suerte de nivelación ontológica cuya consecuencia ética es prestar relevancia a la pluralidad de las formas de ser y a sus caprichosos acoplamientos. Deleuze y Guattari, parecen estar detrás tanto de la propuesta de Haraway como con la de Plant. Es la hora de las multiplicidades complejas que desafían la limitación dual y binaria. Edipo ha muerto. En suma, la dinámica expansiva de la solidaridad una vez que se recusan las coordenadas dualistas parece no tener límite. Se solidariza con todo lo sufriente, con todo lo oprimido y sojuzgado, se compadece con y de los monstruos, de todos aquellos que no responden al modelo de lo apropiado y adecuado, a las prescripciones de la pertinencia acotada culturalmente por los dominadores y por sus metanarrativas deslegitimadas. La máquina binaria produce complejidad y pluralización, se articula como red en la que no hay centro ni periferia, todo está al alcance de la mano. Lazos, vínculos o hipervínculos y redes son las palabras claves del vocabulario por venir donde no hay privilegios de emisor y receptor. Vuelta al mundo de las apariencias, ¿dónde queda la distinción entre lo real y lo ficticio? Estamos más cerca del mundo de Homero que del de Platón, el inventor del abismo entre la imaginación y la razón, el detractor de los poetas. La caverna se troca en laberinto, en suma de laberintos entrecruzados donde encontramos, no uno, sino múltiples hilos de Ariadna para tejer $\mathrm{y}$ destejer conexiones. Las viejas categorizaciones, nuestros mapas conceptuales, deben ser desechadas. Nuevas cartografías efímeras aparecen y se desvanecen para volver a cambiar la faz de las apariencias. Todo fugaz como el parpadeo en una pantalla. Pero todo al servicio de desconectar la cultura de la muerte que no es otra que la del poder. Hagamos resonar de nuevo las palabras que María Zambrano pone en boca de Antígona cuando reprende duramente a sus hermanos fratricidas:

"Sí teníais que morir y que mataros. Los mortales tienen que matar, creen que no son hombres si no matan. Los inician así, primero con los animales y con el tiempo y con ese grado de pureza que llevan dentro. Y enseguida con otros hombres. Siempre hay enemigos, patrias, pretextos. 
Creen que matando van a ser los Señores de la Muerte. El Rey no lo es si no ha matado, si no mata, si no sigue matando....

Y no basta. Hay que matarse por el poder, por el amor. Hay que matarse entre hermanos por amor, por el bien de todos. Por todo. Hay que matar, matarse en uno mismo y en otro. Suicidarse en otro y en sí con la esperanza de ser perdonado por tanto crimen, por tanta muerte expandida.

El Señor de la Muerte tiene que matarse al fin, si algo tiene dentro vivo en la experiencia del perdón.

Para eso hay tiempo, todo el que haga falta.

Para vivir no hay tiempo.” (Zambrano, 1989: 72)
¿Qué vínculo más poderoso hay que buscar que el oponerse a la cultura de la muerte? La afirmación masculina a través de la muerte - el hegeliano arriesgar la vida para ganarla o la autenticidad del ser-para-lamuerte heideggeriano- debe ser aniquilada para dar paso a la celebración de los lazos: la solidaridad celebra la afinidad y el vínculo, lo crea y lo recrea y desactiva las fronteras y los litigios que se coagulaban frente a ellas. Esta es, al menos, la pretensión de las propuestas eco y ciberfeministas con las que nos hemos entretenido.

\section{Conclusiones}

La conclusión a la que llegamos es que la utopía de un mundo postgenérico, propuesto desde un ímpetu liberador ligado a las bio/ciber/tecnologías, no puede renegar de la ecología y de la cultura de la vida. Evaluamos, por lo tanto, el giro posthumanista desde criterios normativos igualitaristas y sostenibles.
Sirva este texto como homenaje a aquella tejedora de sueños y de razones que fue Mary Shelley -la madre de Frankenstein-.

Este artículo, como el monstruo de Frankenstein, ha sido realizado cosiendo pedazos de texto, retales, al modo de una colcha de patchwork. 


\section{Referencias}

Este trabajo se inserta en el proyecto I+D "Diferencias genérico-culturales y desigualdades económicas" (HUM2007-650099/FISO) del Ministerio de Educación y Ciencia de España.

ALAIMO, S. (1994): “Cyborg and Ecofeminist Interventions: Challenges for an Environmental Feminism" en Feminist Studies, Vol. 20, n 1, Spring, pp. 133-152

AMORÓS, C. (1992): "Misoginia romántica" en BIRULÉS, F. (ed.), Filosofía y género. Identidades femeninas. Pamplona, Palmiela.

DONOVAN, J. (1993): "Animal Rights and Feminist Theory” en GAARD, G. (ed.): Ecofeminism, Women, Animals, Nature. Temple University Press

ECHEVARRÍA, J. (1994): Cosmopolitas domésticos. Barcelona, Anagrama

---, (1996): Telepolis. Barcelona, Anagrama

GAARD, G. (1993): "Living Interconnections with Animals and Nature" en GAARD, G. (ed.): Ecofeminism, Women, Animals, Nature. Temple University Press

GÓMEZ, A. (1998): "De la mujer en la ciencia a las epistemologías feministas” en GÓMEZ, A.; TALLY, J. (eds.): La construcción cultural de lo femenino. Instituto Canario de la Mujer, pp. 211-251

GUATTARI, F. (1996): Las tres ecologías, Valencia, Pretextos

HARAWAY, D. (1995): Ciencia, cyborgs y mujeres. La reinvención de la naturaleza, Madrid, Cátedra, 1995 (Ed. orig. 1991)

HOLLAND-CUNZ, B (1996): Ecofeminismo, Madrid, Cátedra

KELLER, E. F. (1991): Reflexiones sobre género y ciencia. Valencia, Ed. Alfons le Magnanim

JAGGAR, A. (1998): "Globalizing Feminist Ethics?” en Hypatia, vol. 13, n 2, Primavera, pp. 7-31
MADRID, M. (1999): La misoginia en Grecia. Madrid, Cátedra

MELLOR, M. (1997): "Un socialismo verde y feminista: la teoría y la práctica." en Ecología Política, $\mathrm{n}^{\mathrm{o}} 14$, pp. 11-22

MIES, M. (1997a): "Investigación feminista: ciencia, violencia y responsabilidad” en M. MIES; V. SHIVA, Ecofeminismo, Barcelona, Icaria

----, (1997b): "El dilema del hombre blanco: su búsqueda de lo que ha destruido" en M. MIES; V. SHIVA, Ecofeminismo, Barcelona, Icaria

MIES, M. (1997c): “¿Quién ha hecho de la naturaleza nuestro enemigo?” en M. MIES; V. SHIVA, Ecofeminismo, Barcelona, Icaria

PLANT, S. (1998): Ceros +Unos. Mujeres digitales + la nueva tecnocultura, Barcelona, Ed. Destino

ROSNAY, J. de (1996): El hombre simbiótico, Madrid, Cátedra

SHIVA, V. (1995): "La mujer en el bosque" en Abrazar la vida. Mujer, ecología y desarrollo. Madrid, Horas y horas, pp. 99-149

----, (1997): "El mito de la recuperación del retrato en el desarrollo" en M. MIES; V. SHIVA,

Ecofeminismo, Barcelona, Icaria

ZAMBRANO, M. (1989): La tumba de Antígona, Madrid, Mondadori

\section{Cita de este artículo \\ GUERRA PALMERO, M. J. (2011) La (des)conexión mu- jeres y naturaleza: propuestas eco y/o ciber-feministas. Revista Icono14 [en línea] 1 de enero de 2011, Año 9, Vo- lumen 1. pp. 21-38. Recuperado (Fecha de acceso), de http://www.icono14.net}




\section{NOTAS}

${ }^{\text {i }}$ La anorexia reinante hoy parece la consecuencia de saberse defectuosa al no entrar en el lecho de Procusto de la talla 38 .

${ }^{\text {ii }}$ Cf. las siguientes compilaciones, monográfico, Mientras tanto, ${ }^{\circ}$ 65, pp. 17-138. Otras interesantes compilaciones son G. GAARD (ed.), Ecofeminism. Women, Animals, Nature. Philadelphia, Temple University Press, 1993, e I. DIAMOND; G.F. ORENSTEIN (eds.), Reweaving the World. The Emergence of Ecofeminism, Sierra Club Books, 1990.

${ }^{\text {iii }}$ Un esquema de las diferentes opciones a partir de la opción política de los feminismos lo ofrece Carolyn. Merchant en "Ecofeminism and Feminist Theory" en I. DIAMOND; G.F. ORENSTEIN (eds.), Reweaving the World. The Emergence of Ecofeminism, ed. cit., pp. 100-105.Cf., también, B. HOLLAND-CUNZ, Ecofeminismos, Madrid, Cátedra, 1996.

${ }^{\text {iv }}$ Hemos alterado su orden para adecuar su descripción a nuestro objetivo expositivo.

${ }^{v}$ Cf. MERCHANT, C. (1980): The Death of Nature: Women, Ecology and Scientific Revolution. New York, Harper \& Row

${ }^{\text {vi }}$ Cf. KING, Y. "Healing the Wounds: Feminism, Ecology and the Nature/Culture Dualism.” en I. DIAMOND; G.F. ORENSTEIN (eds.), Reweaving the World. The Emergence of Ecofeminism, ed. cit., pp. 106-121

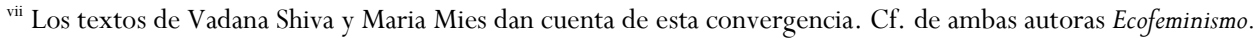
Teoría, crítica y perspectivas. Y La praxis del ecofeminismo. Biotecnología, consumo y reproducción. Barcelona, Icaria, 1997 y 98 , respectivamente.

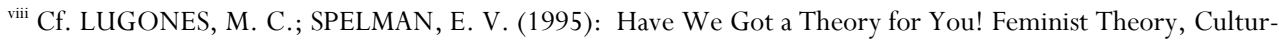
al Imperialism, and the Demand for “The Woman's Voice” en TUANA, N.; TONG, R. (eds.): Feminism \& Philosophy. Essential Readings in Theory, Reinterpretation, and Application. Westview Press, pp. 494-507.

${ }^{\text {ix }}$ Cf. la narración de la experiencia de las madres de niños y niñas pequeñas post-Chernobil en MIES, M. “¿Quién ha hecho de la naturaleza nuestro enemigo?” en MIES, M.: SHIVA, V. op. cit., pp. 137-145.

${ }^{x}$ Ejemplo de la problematización de este cruce lo ofrece SLICER, D. (1995): "Is There an Ecofeminism-Deep Ecology “Debate”?" en Environmental Ethics, vol. 17, 2, Summer, pp. 151-69.

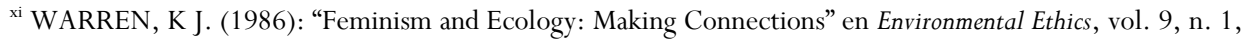
primavera de 1987. Citado en B. Holland Cunz, Ecofeminismos, Madrid, Cátedra, 1996, p. 53.Cf. también B. Agarwal, "The Gender and the Environment Debate: Lessons from India.” Feminist Studies, vol. 18, n. 1, primavera de 1992 .

xii Una reconstrucción del debate entre posturas eco y ciber feministas la ofrecía hace más de una década ALAIMO, S. (1994): "Cyborg and Ecofeminist Interventions: Challenges for an Environmental Feminism” en Feminist Studies, Vol. 20, n 1, Spring, pp. 133-152 